\title{
MONEDA Y CRISIS: UN ENFOQUE
}

\author{
Marcos Cueva*
}

Fecha de recepción: 17 de enero de 2014. Fecha de aceptación: 30 de abril de 2014.

\begin{abstract}
RESUMEN
Este trabajo muestra cómo han quedado adulteradas dos de las funciones de la moneda: medida del valor y del medio de liberación de deudas. La moneda ya no puede tener como referente visible el trabajo ni remitir tampoco al intercambio, con lo que éste supone deuda y obligaciones recíprocas. La medida del dinero puede perderse y la representación del valor está alterada o no existe: suele depender de un estatus dado por la capacidad de adquisición. Este cambio - que pasa también por la representación de la confianza en y el poder del dinero- consiste en desconocer la deuda que encierra la moneda como relación y en privilegiar en exclusiva la realización del beneficio. Este fenómeno se origina tiempo atrás en la subordinación de la gran divisa internacional a intereses particulares, aunque hoy parezcan ser la voluntad general.
\end{abstract}

Palabras clave: moneda, historia monetaria, sistema monetario, dinero, marco teórico. Clasificación JEL: E32, E42, D46, B41.

\section{An Approach to Currency and Crisis}

\begin{abstract}
This work demonstrates how two functions of currency, its measure of value and its role as a means of release from debt, have been weakened. Currency no longer has labor as a visible model, nor can it adhere to exchange, leading to debt and reciprocal obligations. The measure of money is thus lost and its representation of value is altered or no longer exists; it tends to depend on a status determined by its purchasing capacity. This change, which is also related to confidence in and the power of money, consists of disregarding the debt surrounding the currency and exclusively prioritizing the realization of benefits. This phenomenon dates back to the subordination of the major international currency to private interests, which now seem to be the general will.
\end{abstract}

Key Words: Currency, monetary history, monetary system, money, theoretical framework.

* Instituto de Investigaciones Sociales-UnAM, México, cuevaperus@yahoo.com.mx 


\section{MONNAIE ET CRISE : UN ANGLE D'APPROCHE \\ Résumé}

Ce travail montre comment ont été altérées deux des fonctions de la monnaie : celle de mesure de la valeur et celle de moyen de libération de dettes. La monnaie ne peut plus avoir comme référent visible le travail ni renvoyer non plus à l'échange, avec ce que celui-ci suppose de dette et obligations réciproques. La mesure dans l'argent peut se perdre et la représentation de la valeur est altérée ou n'existe pas : il dépend usuellement d'un statut qui est donné par la capacité d'acquisition. Ce changement - qui passe aussi par la représentation de la confiance dans le pouvoir de l'argent - consiste à ignorer la dette que renferme la monnaie comme relation et à privilégier exclusivement la réalisation du bénéfice. Ce phénomène trouve son origine dans le passé, dans la subordination ce la grande devise internationale à des intérêts particuliers, même s'ils semblent être aujourd'hui la volonté générale.

Mots clés: monnaie, histoire monétaire, système monétaire, argent, cadre théorique.

\section{MOEDA E CRISE: UM ENFOQUE \\ Resumo}

Neste trabalho se mostra como foram adulteradas duas das funçóes da moeda: a de ser medida de valor e a de meio de liberaçáo de dividas. A moeda já não pode ter como referencial visível o trabalho, nem se remeter tampouco ao intercambio, com o que este supóe de dívida e de obrigaçóes recíprocas. A medida no dinheiro pode se perder e a representação do valor está alterada ou não existe: costuma depender de um status que está dado pela capacidade de aquisição. Esta mudança - que passa também pela representação da confiança no poder do dinheiro - consiste em desconhecer a dívida que confina a moeda como relação e em privilegiar, exclusivamente, a realização do lucro. Este fenômeno tem origem, já há algum tempo, na subordinação da grande divisa internacional à interesses particulares, ainda que hoje pareçam ser a vontade geral. Palavras-chave: moeda, história monetária, sistema monetário, dinheiro, marco teórico.

货币与危机：一个焦点问题

摘要

本文研究显示货币的两项职能即作为尺度和债务偿还手段已经弱化。货币 不再具有凝结具体劳动的职能, 也不再坚持交换的原则, 这两点正是导致 债务和承担互惠责任。因而, 货币丧失了价值尺度职能, 它所代表的价值 以及被改变或不复存在, 其价值取决于货币本身的购买力了。这种变化与 对货币的信心以及货币的权力有关，而与债务的货币种类无关。这类现可 追溯到世界主要货币的等级关系问题。

关键词：货币货币史货币体系货币财产理论框架 


\section{INTRODUCCIÓN}

Michel Aglietta, André Orléan y otros autores más sostienen que la moneda no se ha limitado en la historia a facilitar el intercambio: es más que eso, y también permite redimirse de una deuda "primordial" u "originaria" con el don de la vida -los autores recogen aquí la tesis clásica de Marcel Mauss sobre el don. Así, "la moneda es un vínculo social de doble faceta: el de la necesidad y la obligación; por un lado, el de la apertura al intercambio, y a la confianza, por otro lado" (Aglietta; Orléan et al., 1998: 21). La primacía del dólar ha roto, sin embargo, este vínculo al desconocer la deuda-obligación y al dejarse de "abrir" al intercambio, lo que confirma, por lo demás, otra idea de los autores: "librado a sí mismo, es decir, que no ordenado por la autoridad, el poder corrompe la cohesión social" (ibid: 23). La sociedad ya no está unida en la deuda-obligación con la vida porque existe, y a lo sumo las partes se encuentran -en teoría- casi casualmente entre sí, con una supuesta espontaneidad, la de un mercado transhistórico, y en la utilidad y la coincidencia-ocasional- de valores subjetivos, o por simples preferencias, si se quiere.

Ahora bien, este poder sin autoridad ni norma por encima de él entraña la imposición de términos privados o particulares -incluso en la manera de pensar y seleccionar los problemas, y a veces hasta de "valuarlos" o evaluarlos-, y no considera necesario lo que el economista belga Robert Triffin llamara el "compromiso de redención" (Triffin, 1962: 38) de una deuda: hoy es un poder des-obligado que incluso se ostenta como tal. Si la moneda tiene un estatuto de "operador de la pertenencia social" (Aglietta; Orléan et al., 1998: 10), el estatus y la pertenencia a un grupo o un país que se considera por encima de los demás -lo ha venido diciendo Estados Unidos, "nación indispensable" desde la presidencia de William Clinton- pasa por la negación de esta deuda: negarse a saldarla "redimiéndose" es hoy signo de estatus, de pertenencia directa o indirecta al país-potencia y una prerrogativa para ejercer poder, percibido como privilegio -el dólar lo tiene, y es exorbitante. El interés general está subordinado al particular, aunque éste se haga pasar por aquél: un particular consigue así, aun debiendo, hacer creer que le es debido por ser "lo común". Lo que es bueno para Estados Unidos debe serlo para el mundo, no al revés.

Hay riesgos en este enfoque, y hemos planteado dos problemas históricos para sugerir que "no estar en deuda", pero recibir crédito o confianza, parece algo que no tiene fin, aunque pudiera tal vez tenerlo: sucedió en la Alemania de Weimar, cuando la moneda perdió toda medida debido a un proceso de hiperinflación, y también hay una anomalía en lo sucedido luego de que el patrón oro fuera remplazado por el patrón cambio-oro, después por el oro- 
dólar -en crisis por lo menos desde 1957-1960, según lo mostrara Triffin (1968: 48, 59-63)- y, finalmente, por el "golpe" de Estados Unidos en 1971. Es posible plantear que algunos de los problemas actuales de la economía internacional $-\mathrm{y}$ del modo en que es vivida y reproducida en distintas escalas- se remontan hasta los años veinte, con el abandono definitivo del patrón oro a secas -si bien hay distintas interpretaciones, y no se pretende tener la única. Hay antecedentes de periodos en los cuales la moneda dejó de ser "medida" y de "redimir".

Partimos de la idea -ciertamente sujeta a un debate que está abierto- de que la moneda se crea en la producción, lo que es tanto como decir (el punto de partida es Smith, no Marx), que la moneda vuelve conmensurables productos del trabajo (trabajo coagulado), permitiendo enumerarlos. Así, la economía política clásica constituye un telón de fondo que es en parte el marco teórico aquí, ya que permite considerar la presencia de categorías y supone entonces un lugar filosófico, igualmente: en efecto, una categoría, a nuestro juicio, sigue siendo un modo de aproximarse a la realidad, aunque ésta no pueda nunca ser mostrada exactamente tal cual es (suponiendo además que esté fija, lo que tampoco es posible). Como sea, si categorizar es posible, la moneda puede tener propiedades, más allá del modo en que es percibida: éste es nuestro planteamiento de partida y el enfoque teórico subyacente (filosófico). Así, la medida está no en la envoltura que es la moneda misma, sino en el trabajo.

Otra cosa es decir que la moneda o el dinero simbolizan "la riqueza", sin especificar su origen, por lo que se enumera dinero y no trabajo. Así se prefiera evitar la referencia al "valor sustancia", es posible afirmar, como lo hace Orléan, que la moneda es una unidad de cuenta que, nótese bien, "da sentido y realidad a la evaluación" (ibid: 185). Pensamos que es posible evaluar el trabajo, algo distinto de "ponerle precio" al producto, hasta donde el precio, aún con características propias, es una manifestación del trabajo que no forzosamente coincide con éste, algo también señalado desde Smith. Para Orléan, la moneda es en todo caso "la institución del número mercantil", aquello por lo cual las relaciones mercantiles se encuentran "plenamente instituidas como relaciones enumeradas" (ibid: 185). Está abierta aquí la posibilidad de pensar una norma. Lo que se plantea, y que difiere de Orléan y su búsqueda sociológica, por ejemplo en la "confianza" según Georg Simmel (ibid: 190-196) es que el sentido puede perderse si no hay "dato objetivo intrínseco" en común (el trabajo) que limite la fuerza-potencia de la enumeración, que puede querer decir entonces "cualquier cosa". Así, la norma puede perderse de vista, y no es raro que suceda en la historia, donde no hay una norma estable de una vez y para siempre: este es el segundo aspecto de nuestro planteamiento, y es 
que, para decirlo en palabras de Georges Canguilhem, lo "patológico" puede imponerse a la norma (lo cual no siempre es peyorativo: es parte más bien de un movimiento que tiene lugar por desequilibrios, antes que por tendencia al equilibrio, afirmación que no es inocente ni en la ciencia, ni en la ciencia económica en específico). También polemizó en su momento para mostrar que una enfermedad puede tomar distintos rumbos, desde desaparecer de inmediato hasta prolongarse, desde sanar y cambiar al organismo enfermo hasta matarlo, dependiendo en mucho de factores como, por ejemplo, el reconocimiento de la anomalía o del "error" por parte del organismo en cuestión (Canguilhem, 2005). A falta de certeza absoluta sobre el futuro, y como por lo demás no es función de la ciencia profetizar, la analogía, aunque "biologicista”, ayuda a nuestro modo de ver a ubicar al análisis sobre las crisis.

Este trabajo tiene entonces por objetivo mostrar algunos aspectos de una historia monetaria moderna donde sucede que la patología no sólo se impone a la norma, sino que parece incluso destruirla: según veremos, como parte de lo buscado aquí, esta "patologización" de la moneda encuentra expresiones subjetivas e incluso en el modo en que la ciencia (la social incluida) se representa a sí misma. En esta medida, y también porque hay formas distintas de vivir subjetivamente una crisis, cabe la posibilidad de hacerse preguntas antropológicas sobre este "ser" en la patología económica. Se sugiere que en los años veinte del siglo $\mathrm{xx}$, en el origen del abandono de una "norma" monetaria, lo que empieza a cambiar es lo siguiente: no son las estimaciones privadas las que se sujetan a una común para todas (como el oro), una norma objetiva, sino que una de ellas se hace pasar por "lo común". Triffin escribía que el absurdo básico del patrón de cambio-oro estaba en hacer depender un sistema monetario internacional de decisiones sobre una o unas cuantas monedas nacionales como reservas monetarias (1962: 87). Aquí se ha sembrado la confusión, ya que será lo particular y no lo general lo que se tomará como norma, hasta desembocar, desde finales de los años sesenta del siglo pasado, en el estallido de esa misma norma. El mundo monetario internacional no tiene una nueva. Si se quiere, aquí la hipótesis es que lo ocurrido en los años veinte (y sellado con la decisión estadounidense de 1971) terminará por pervertir la representación de lo que es un orden monetario internacional con "normatividad".

En este trabajo se plantea que este vivir sin norma común, menos aún explícita, pero con intereses particulares que se han hecho pasar por lo general, es algo que ha echado raíces incluso en las ciencias sociales, no sin problemas, y para beneficio de un cientismo que no siempre es la ciencia que cree ser: es el origen del relativismo axiológico que también se encuentra en los años veinte del siglo pasado, y que reaparecerá más tarde, por lo que consideramos 
oportuno reexaminar lo sucedido en el periodo de entreguerras de ese siglo. Nuestra hipótesis es que se encuentra en este periodo, en parte, el origen de las patologías monetarias actuales (pese a un periodo de estabilidad de unos 20 ańos en la posguerra), aunque no quepa adelantar el advenimiento de alguna nueva norma, ni especular demasiado sobre la forma que pudiese tomar. Por lo pronto, es lo patológico que se ha instalado de algún modo como normal, fenómeno que también remite al periodo de entreguerras del siglo $\mathrm{xx}$, al menos hasta donde la analogía es un procedimiento válido (puesto que tiene ciertamente sus límites).

\section{I}

En la crisis actual es frecuente oír -al menos entre las generaciones que vivieron a plenitud la Edad de Oro de la segunda posguerra- que "todo es dinero". ¿Este supuesto sentido común es indicativo de algo? Para muchos, no es que no haya valores; es que no debe haberlos donde impera el relativismo y proliferan las diferencias: a lo sumo, el valor es algo subjetivo (cualquier economista reconoce el origen de esta afirmación) y depende de "cada quien". No nos parece inocua -es lo que se demuestra en este texto- la creencia, aún en medio de la diversidad de todo, de que, por decirlo de algún modo, no hay medida común posible. No hace falta demostrar que en la economía internacional hay mucho sin medida o equivalencia: la especulación no tiene relación aparente con los intercambios reales, los déficit gemelos estadounidenses ni siquiera tienen relación con el sentido común en los números, con el de "la medida" [...] Si el tema es de actualidad, aducir que "todo es dinero" o que el "libre mercado" es la solución quiere decir muy poco o nada, máxime que hay mercado y dinero diríase que casi desde tiempos inmemoriales -o al menos desde que hay moneda e intercambio. Este tipo de discurso sirve poco para aprehender la especificidad de la crisis actual, ya que es un discurso transhistórico: las cosas "siempre fueron asi" -es de suponer-y lo serán tal vez para la eternidad. Dicho de otro modo, es un discurso cuasi-religioso que llama a la resignación, o a constatar -como lo hacía el viejo absolutismo- que "poderoso caballero es Don Dinero", como si en ello se hubiera perdido el alma. ¿"Todo es dinero" o es que "nada tiene valor" y, por ende, "todo se vale"? Hay un matiz.

Que hoy "todo es dinero", es inexacto, aunque revela algo. Así, la racionalidad que se impone es económica -ciertamente, y no siempre fue así. Ni siquiera tiene mayor sentido hablar de capitalismo en general, como si fuera siempre idéntico a sí mismo. No hay racionalidad económica en general, ni 
"de mercado", y si se admite que el capitalismo reina un poco por doquier, la misma racionalidad, suponiendo que sea tal, se guía por la ganancia (y no por el dinero), lo que por momentos convierte a la vulgata económica en crematística y al "hombre económico" en alguien aquejado de pleonexia. ¿El dinero se entiende entonces de un modo peculiar y, mientras hay patrón dólar, se dará por sentado que en la estimación privada se puede ganar sin perder nunca nada, pasándole la factura al "resto"? ¿Este es el "valor socialmente reconocido", por lo que, siguiendo a Orléan, la gente quiere dinero, no valores de uso, ya que con dinero se puede "cualquier cosa"?¿Dónde sucede -si es así- que "cualquier cosa" pierde sentido y se vuelve fantástico pero también peligroso? También sugiere que "todo camina" mientras la mercancía conserva sus cualidades monetarias y su propietario puede comprar las mercancías que quiere, cuando quiere (Orléan, 2011: 191). Pero ocurre que a veces no es así, o que no siempre lo ha sido.

\section{II}

Alemania se había sentido humillada por la Paz de Versalles y, por cierto, Keynes advirtió sobre las consecuencias negativas de las reparaciones que se le habían impuesto al país vencido. En 1923, los alemanes se sintieron de nueva cuenta sobajados, esta vez por la hiperinflación -aunque se olvida que frente a los consejos de Keynes, más de un alemán prefería seguir con el proceso hiperinflacionario como forma, nótese bien, de no reconocer la deuda que entrañaban las reparaciones, por lo que se "dejaba pasar" (Friedrich, 1995: 133134 y 136). Para muchos, con todo, incluyendo una clase media que creía que "el oro es para la defensa, y el hierro para el honor" (Friedrich, 1995: 120), de la noche a la mańana, "millón" ya no quería decir nada. ¿Podría agregarse que la idea de ser una gran potencia se desvanecía con la evaporación del marco? Los alemanes, escribió Elías Canetti, se sentían "humillados en el descrédito de sus millones" (1981: 181). Y hace notar que hay mucha cercanía entre masa y dinero, y que, por lo demás, "quizás la confiabilidad de la moneda sea su característica principal” (1981: 180). Denigrados, los alemanes ya no tenían un valor en el cual confiar -aumentaba la masa pero se perdía el valor. Canetti resulta muy agudo al observar el tipo de reacción que este fenómeno desencadenó: rebajado cada uno en su singularidad, y como colectivo, los alemanes optaron por ese comportamiento más o menos sistemático. Así, "es preciso, escribe Canetti, tratar algo de manera que valga cada vez menos, como la unidad monetaria durante la inflación, y este proceso debe continuar hasta que 
el objeto haya llegado a un estado de completa ausencia de valor" (Canetti, 1981: 183). Lo que dice es, a fin de cuentas, que los alemanes, como masa, perdieron en la inflación la noción de valor, la de ellos y la de los demás, lo que sucedió paradójicamente en los "años locos". Los millones ya no eran tales; sólo se llamaban así, dice Canetti, sin que el nombre correspondiera entonces a un valor real. El autor va más lejos, puesto que observa que, en medio de lo ocurrido, el judío apareció como "el que estaba bien con el dinero" (ibid: 184). Había que rebajarlo.

El autor no reduce el problema alemán en los años veinte al dinero. No es así, menos cuando recuerda la importancia que tenía para Alemania el ejército desde la guerra franco-prusiana de 1971 (la potencia por la fuerza). Pero el dinero "cuenta", valga la expresión, más en una sociedad de masas. ¿Qué ocurrió? Según este autor, que Hitler llegó a regodearse en "[...] el placer voluptuoso del número que crece de golpe" (ibid: 181), por lo que el führer, en sus discursos, frecuentemente lo contaba todo por "millones": digamos que había que restablecer la potencia, aunque se había perdido la noción de valor. Masa, potencia y fuerza no tenían mucho que ver con el valor como "medida"; Hitler calculaba sin medida, un Reich de 1000 años, por ejemplo. Estaría claro entonces que el nazismo se comportó en la segunda guerra mundial como quien desconoce el valor de la vida, más tratándose de la de un ser designado como "inferior": los muertos en los campos de concentración eran objetos sin valor (o, en el peor de los casos, "materia prima").

Otto Friedrich ha hecho notar que en 1923 no se perdía nada más la idea del valor de una moneda; también se evaporaba la idea de sociedad, ya que ésta se desintegraba.

La cualidad fundamental del desastre -escribe Friedrich- era una pérdida completa de la fe en el funcionamiento de la sociedad. La moneda es importante no sólo como medio de intercambio económico [...] sino también como un estándar por el cual la sociedad juzga nuestro trabajo, y entonces a nosotros mismos. Si la moneda se vuelve carente de valor, lo mismo pasa con el gobierno, y con toda la sociedad, y con todos los estándares. En la locura (madness) de 1923, el trabajo de un trabajador era algo carente de valor, los ahorros de una viuda eran algo sin valor, todo era carente de valor" (1995: 126).

El colapso era más corrosivo que el que hubiera producido algún evento político (ibid: 127). 
Habida cuenta de los cambios que han tenido lugar en la economía internacional desde varias décadas, no es raro que el dinero suela ser percibido o "tomado en cuenta" sin mayor relación con el trabajo. Lejos está la economía política clásica, por más que haya "neoliberales" que reivindicaran a Adam Smith, al menos hasta 2008. Si éste fue el primero en hacer del trabajo el pilar de la riqueza social, parecería incluso certero el título de un libro de Giovanni Arrighi, Adam Smith en Pekin, ya que China es hoy para muchos el taller del mundo. Pocos negarían que la riqueza china se vinculara al "sudor de la frente". Sin embargo, buena parte del poder económico ha permanecido en otra parte, Estados Unidos, pese a la pérdida de competitividad de su economía, a la mala calidad de muchos trabajos en ese país e incluso a la desertificación industrial y otras formas de deterioro. El poder no es el trabajo: es, en apariencia, el de un dinero que además pretende no tener mayor relación con el trabajo mismo (Wall Street no es el "sudor de la frente", sino que es, más bien, un templo, y si es así, una religión y, tal vez, una ideología que reclama "confianza").

Lo señalado hasta aquí no es ajeno ni al modo en que es vivida la economía, ni al modo en que suele presentarse la ciencia económica, ni a debates sobre la moneda que, por cierto, no pretendemos zanjar. No pensamos que la economía sea un lugar absolutamente transparente donde no hay distancia entre lo pensado o representado (no es lo mismo) y la realidad -como si no hubiera entonces más que reproducirla neutramente sin pensarla ni transformarla, algo que invita a reproducir e incluso a ejercer poder. Tampoco pensamos que el único medio o la garantía para acortar la distancia entre lo pensado y la práctica sea el número (la cuantificación: ¡el empirismo no es a veces coartada que confunde la experiencia con lo sensible?).

Este planteamiento tampoco es del todo nuevo. Ya lo había hecho en su momento alguien como Jacques Rueff, crítico acérrimo del patrón oro-dólar y del patrón cambio-oro (al igual que Robert Triffin) y, más aún, de lo que fue preparando el acontecimiento clave para este estudio: la supresión del patrón oro-dólar en 1971, con Richard Nixon en la presidencia estadounidense. Pasadas varias décadas desde entonces (y desde que Milton Friedman asesoró a Nixon en la decisión), es posible, a nuestro juicio, establecer el efecto de tal medida, no nada más en la economía internacional, sino también en la forma en que es percibida por quienes la viven o incluso deciden en ella. 
Para comprender este apartado, es preciso dar por sentado que no hay moneda mundial ni supranacional -lo que fue por lo demás una derrota para Keynes. Desde el momento en que una moneda particular (un interés particular) se hace pasar por general, universal o "global" (o por una voluntad general), lo que hay en la práctica es un mecanismo de dominación, más o menos justificado o legitimado. Se trata de dominación por la asimetría implicada en que uno pueda hacer lo que otros no, tener su moneda como divisa internacional y, además, que sea la principal. Si no hay moneda mundial, tampoco hay manera de volver conmensurables las monedas nacionales: la dominación consiste, entre otras cosas, en no dar el equivalente de lo recibido, lo que es tanto como decir que no hay igualdad (no es porque un interés privado parece general que hay igualdad real).

Jacques Rueff -a quien se ha querido retratar como el conservador que no era, ya que pertenecía más bien al liberalismo de origen decimonónico- veía el origen de muchos problemas económicos internacionales en los años veinte, y no en el patrón oro-dólar por sí mismo, aunque lo criticara. Para él, el problema se había instalado en el abandono del patrón oro, medida que debía ser temporal, a principios de esos años (en particular con lo acordado en la Conferencia Monetaria Internacional de 1922), y la situación ya era preocupante entre 1926 y 1929, como iba a serlo entre 1958 y 1961 -lo reconoció hasta cierto punto John F. Kennedy el 6 de febrero de 1961. El "juego" en la segunda mitad de los años veinte - para beneficio de la libra esterlina y el dólar- era algo parecido al estadounidense de hoy [...]. Por lo demás, aunque en otra escala, la evolución del crédito y del poder de compra se disoció -como sucede hoy en Estados Unidos y en algunos otros espacios de la economía internacional- del referente real que encerraba el oro, y también de la expansión económica y de la riqueza real (Rueff, 1971: 44). Esta disociación creó la idea de que es posible obtener beneficios sin pagar por ellos, y se llegó a identificar un patrón de medida y costo, algo cierto. Rueff-quien participó con Ohlin en debates sobre las reparaciones alemanas que involucraron también a Keynessacó conclusiones sobre el orden social. No creía que un ente pudiera instalarse indefinidamente en la "estimación arbitraria" -entiéndase que caótica- sin toparse entonces nunca con alguna "magnitud objetiva" (Rueff, 1964: 321), por más que algunos gobiernos se volvieran duchos en "poner de manifiesto el beneficio y disimular el coste" (Rueff, 1964: 562), fuera en privaciones o en sacrificios, creando así la fantasía ya no del máximo beneficio al menor coste, sino del beneficio sin coste alguno. La creencia en que la medida o magnitud 
objetiva desaparecería se basaba para Rueff en "falsos derechos", definidos a priori, e incluso con "ilusiones contables" (Rueff, 1964: 321). Insistió en lo que significaba desde principios de los sesenta el déficit estadounidense con el patrón oro-dólar como referente: un "déficit sin lágrimas" (Rueff, 1971: 23), un costo que parecía posible de esquivar. Este secreto "[...] permite dar sin tomar, prestar sin pedir prestado, y adquirir sin pagar" (ibid: 24); "el descubrimiento de este secreto -estima Rueff- ha modificado profundamente la psicología de los pueblos, atenuando o suprimiendo, para los beneficiarios de la moneda bumerán, las consecuencias internas que el patrón oro atribuía a los déficit en la balanza de pagos" (ibid: 24). Todo lo que Rueff llama la "política del don" está alterado, y es posible pensar que con consecuencias incluso antropológicas, dado que Rueff se refiere a la psicología de los pueblos: un déficit o un costo no traen consecuencias, y se abre incluso la posibilidad de reportarlas sobre otros. El circuito que consiste en dar-recibir-devolver está cambiado por otro: tomar, rechazar la devolución (no devolver), guardar. Rueff lo dijo también de otro modo: desde principios de los sesenta, anunciaba la insolvencia de Estados Unidos, pero también que este país quedaba dispensado de saldar sus deudas con el extranjero (ibid: 82). La insolvencia pasó a parecer algo sin consecuencias, hasta que se volviera signo de estatus no hablar nunca de ningún costo (¿ni preguntarse siquiera por la solvencia?). Lo mismo sucedió con la costumbre de hacerse sujeto de crédito-confianza reservándose el derecho a no pagar-devolver-a -no "redimir" ninguna deuda ni cumplir obligación ninguna. Aquí no hay definición válida per se: en la primera mitad del siglo xx parecía ser la productividad de la economía estadounidense la que respaldaba el patrón cambio-oro y oro-dólar, y había por ende una medida, el trabajo; desde la segunda posguerra -a finales de los años cincuenta- se anunciaba otra lectura del poder estadounidense y la confianza en Estados Unidos (Triffin, por ejemplo, hacía ver la fuerza militar).

Bernard Schmitt lo formuló a su manera, partiendo de la idea de que la moneda es creada en la producción. Con el monopolio de la emisión de una moneda internacional (por relativo que sea), Estados Unidos se permite exportar una moneda, el dólar, que es bumerán porque regresa al sistema bancario estadounidense del que en realidad no ha salido. En el extranjero, "pagado (i) en dólares, el país acreedor recibe no un pago, sino la prueba de que no fue pagado" (Schmitt, 1977: 191). A partir de ahí se monta la especulación con los papeles de "no pago", en detrimento de quienes perciben un ingreso (ibid: 191). Como ya había sucedido, luego de 1922, para beneficio de la libra y el dólar, se trata de algo que Rueff describe como un juego de canicas en el cual los niños le devuelven lo apostado al perdedor (Rueff, 1971: 23). 
También constata que en los años veinte "[...] por el regreso perpetuo de los dólares y las libras recibidos por los países europeos en los países donde emanaban esos recursos, el funcionamiento del sistema monetario internacional se encontraba reducido a un juego pueril de niños que habrían convenido en devolver lo apostado, después de cada juego de canicas, a quienes lo hubieran perdido" (Rueff, 1971: 23).

En su descripción, los problemas en el paso del patrón oro al gold exchange standard no fueron del todo ajenos al ascenso del nazismo en Alemania. El planteamiento de Rueff, sin embargo, va mucho más allá cuando muestra lo que sucede entre 1958-1961: es todo un cambio "antropológico" que se avecina, en la medida en que el circuito del don está por romperse. Lo explica en términos generales, pero saca también conclusiones particulares que podrían llevar a interrogantes sobre lo que se entiende hoy por Homo Oeconomicus, al menos entre quienes están bajo fuerte influencia del modo de vida estadounidense y lo que éste realmente significa. Lo que duró poco en los años veinte se propagó a partir de 1971, volviéndose incluso algo así como símbolo de estatus.

\section{V}

La hiperinflación no fue la única consecuencia en la Alemania de Weimar. El rebajamiento fue a instalarse en el mundo de las ideas, aunque entonces las ciencias sociales no estaban plenamente consolidadas como tales. De la misma manera en que el valor-trabajo en economía se había evaporado, en algunas corrientes de las ciencias sociales -en el derecho, por ejemplo- llegó a sostenerse que no había verdad posible. La posmodernidad (a partir de los ochenta del siglo xx) no es el único periodo histórico en que haya sido afirmado el relativismo axiológico, que es el supuesto de que todos los valores son relativos. No parece tan casual que sea en un contexto como el descrito por Canetti que aparezca este relativismo, y que se afirme que no hay juicio de valor posible, ya que quien lo hace pretende así tener alguna "verdad absoluta"; se da por sentado que la ciencia "debe ser" neutra, y dicho sea de paso, hay algo de contradictorio en querer sostener el relativismo supuestamente neutral como verdad absoluta y como deber ser, castigando entonces [...] toda desviación del relativismo que es "la" verdad. Contra lo que parece, no es exactamente un asunto ético-normativo, que para algunos científicos debiera ser excluido de una ciencia -la económica incluida- con pretensiones de neutralidad, misma que está siempre cercana a la potencia-número y que reemplaza el pensamien- 
to por el cálculo, que es lo que facilita la conversión de la ciencia económica en crematística.

En realidad, sucede otra cosa con el relativismo, algo que se parece a la desaparición de todo patrón de medida: se ha "perdido la medida" del mismo modo en que en la economía se ha extraviado el "patrón de medida", y cualquier cosa es entonces posible, lo que intuye quien detenta un poder, por pequeño que sea: hay un "sin límite" que se afirma como derecho o incluso como meta, como lo hace la mercadotecnia [...]. Contra algo así alertaba Keynes cuando las reparaciones contra Alemania no tenían "medida". Era algo "fuera de toda proporción", y cuando algo lo es, se está en lo "no razonable", incluso en lo fantástico.

La expresión de lo ocurrido en el derecho se encuentra en Hans Kelsen, quien se guía por una modalidad de positivismo: el derecho es una técnica, pero poco tiene que ver con la justicia o la moral (por lo que Kelsen defiende el iuspositivismo, que se remonta, entre otros, a Jeremy Bentham, un utilitarista). En 1971, en Estados Unidos, Kelsen seguía expresando el "espíritu de Weimar", el relativismo. Retoma el positivismo, por lo que es ciencia lo que se acerca a la física, o parece traducirla: la justicia no es "medible", porque nadie puede establecer un patrón que aspire a ser "absoluto", entiéndase que válido para todos. Lo que no cae en el terreno de esta ciencia asimilada a la física (es el viejo sueño de Comte para la sociología), pasa al terreno de lo subjetivo, donde no hay "imposición posible" y la estimación privada es completamente arbitraria. Un juicio de valor -distinto de una valoración- no remite entonces a la posibilidad de conocer una realidad (y hacer un juicio de realidad) que, por lo demás, tiene existencia objetiva, independiente de la mente de tal o cual. El juicio de valor, aunque guiado por el interés (Kelsen, 1982: 118), se convierte en subjetividad casi pura, luego por cierto sospechosa, porque expresa "la reacción personal emotiva hacia el objeto", los deseos y los temores humanos (ibid: 129) ¿Qué entra en juego en los juicios de valor, según Kelsen? Voluntad, fe, sentimiento, etc., pero no hay nada posible de establecer como racional, fuera del dominio de la ciencia positivista, y cualquier cosa que emane de lo "emotivo" parece difícil de cuestionar o de argumentar racionalmente. Fuera de la ciencia asimilable a la física, de la potencia-número, ninguna racionalidad existe, menos aún en la mente. Lo racional es el número y la utilidad. Fuera del empirismo no hay teoría que valga y se la podrá tachar de ideológica, o incluso de ocurrente o antojadiza.

Este relativismo axiológico (que supone que no es posible jerarquizar entre valores), si no se queda en asunto de que "en gustos se rompen géneros", es menos inocuo de lo que parece. Si llega a encontrar una traducción al dinero, 
es como sugerir "tanto tienes, tanto vales", e inclinar la balanza por un peso que es el del dinero y su fuerza-potencia: donde no hay medida para todos, se impone la potencia-número del más fuerte (que puede ser la mayoría-número).

En los mismos años en que Alemania vivió la hiperinflación, un autor como Ralph Barton Perry se planteó en Estados Unidos el problema de determinar qué es el valor, en particular, desde un punto de vista filosófico (Barton, 1939). ¿Cómo volver conmensurables incluso "valores" distintos? Perry desecha la posibilidad de que sean la verdad, la realidad o la objetividad que permitan saber qué tiene valor, y aduce que, por lo demás, lo que tiene valor debe ser "valuable" (lo que introduce una ambigüedad, sobre todo por el matiz de la palabra en inglés) y cuantificable. Ofrece una solución que no es ajena a la percepción de nuestros días: tiene valor lo que presenta un interés, y desde antes, este autor considerado neorrealista -aunque también debiera ser considerado pragmático, y de hecho sigue a William James- ya ha sugerido que tiene interés "lo deseable". ¿Qué rige ese mundo de valor donde Kelsen no quiere adentrarse demasiado? Para Perry, lo que responda a la pregunta: ¿qué es lo deseable? La pregunta es ante todo individual, aunque lo conmensurable se establece cuando surge un "orden de preferencias" que es, asimismo, la estandarización de intereses. Si el valor es subjetivo, o si es asunto de "preferencias", fácilmente entra en el terreno de la creencia. Es tanto como decir que el valor no puede conocerse, y que a lo sumo tiene "valor" lo que tal o cual desea. No queda más que calcular lo deseable.

En un rumbo similar se encuentra el británico Lionel Robbins, considerado a veces pionero en definir la ciencia económica. No es nada más que Robbins no salga del marco establecido más de medio siglo antes por el marginalismo. Tampoco quiere saber de juicios de valor, así que afirma que "[...] el análisis económico es wertfrei en el sentido weberiano. Los valores que toma en cuenta son valoraciones del individuo. Queda fuera de su alcance si en un sentido ulterior son valoraciones válidas" (Robbins, 1951: 128). Como Kelsen en materia de derecho, Robbins quiere en economía que la ciencia se acerque a la física, explícitamente (ibid: 132). Nótese que, a quienes le reprochan a cierta economía no ocuparse más que de dinero, Robbins contesta de manera contundente que no se trata de ocuparse de "ganancias nominales o en dinero", sino de lo que este autor británico llama "ventajas netas" (ibid: 133), que, dicho sea con ironía, es la ganancia cruda. 
Con el uso frecuente de la mercadotecnia, desde la segunda posguerra del siglo $\mathrm{xx}$, el valor pasa a ser lo que el individuo "le asigna" a lo que compra, y desempeña un papel importante el deseo, que se sustituye al interés o se confunde con él. Así, tiene valor lo que se desea subjetivamente, aunque suele omitirse que la mercadotecnia tiende a moldear el comportamiento del consumidor (por cierto, Milton Friedman, el asesor de Nixon, es también el que hace la gran apología de la "libertad de elegir" del consumidor). El valor no nada más resulta imposible de ser determinado objetivamente; ha salido de la órbita del trabajo para colocarse en la del consumo, no es el valor determinado por el costo del producto. Son las "percepciones del valor que tienen los compradores, no los costos del que vende, como clave para fijar los precios" (Kotler y Armstrong, 2001: 333). En vez de integrar los costos y la utilidad neta para fijar el precio y hacer la mercadotecnia, la fijación de éste parece invertirse: "la compañía - prosigue Kotler- establece su precio meta con base en las percepciones del cliente respecto al valor del producto" (ibid: 334). Así, "la fijación de precios inicia con un análisis de las necesidades y percepciones de valor de los consumidores, y el precio se fija de modo que sea congruente con ese valor percibido" (ibid: 334). Es entonces posible llegar a que tiene valor lo que se prefiere consumir, sea o no el resultado de un esfuerzo o un desgaste. Es el tipo de argumento que se encuentra en los clásicos del marketing y, de hecho, cabe pensar que "el mercado", así como es de vago, remite más a la mercadotecnia (una "economía degradada" en un falso sentido común, que es el de la empresa) que a la ciencia económica (que no es la de la empresa). A lo sumo, según el llamado "marketing social", "los valores son creencias que gozan de un arraigo mayor en la población” (Pérez Romero, 2004: 164). Un juicio de valor se reduce a una creencia -cuando no a un gusto. Se ha llegado a un punto que defiende Orléan: el valor es esencialmente "una potencia de compra que, una vez que ha investido el objeto monetario, se encuentra deseada y reconocida por todos" (Orléan, 2011: 191), sin que parezca importar si el deseo es el de consumir o el de invertir en una empresa. ¿Es un deseo consensuado o mayoritario? En todo caso, la moneda escapa aquí a toda lógica contractual, según Orléan (ibid:193), afirmación que no sería hoy del desagrado de quien posee la divisa clave, el dólar, y que se sirve de ella para no comprometerse en redimir una deuda: en vez de obligaciones, supuestamente está lo que Orléan llama una "polarización mimética de los deseos" que constituye la confianza monetaria (ibid: 193). 
A pesar de que el enfoque del valor propuesto por Orléan es polémico, el mismo autor señala con todo que "[...] la objetividad del valor significa [...] que todos los protagonistas reconocen la misma definición del valer, de tal modo que es posible determinar sin ambigüedad las cuentas que están en excedente y las que están en déficit" (Orléan, 2011: 170). Ahora bien, el tener la propia moneda como divisa internacional permite un déficit "sin lágrimas" que, agreguemos, ni siquiera implica que a quien lo tiene se le retire la confianza-crédito - menos aun cuando el centro tiene el poder de compra y lo redistribuye. Así, este déficit se acompaña no de medidas correctivas, sino de la afirmación de los derechos que da el poder de compra a este mismo centro.

Al haber terminado con el patrón oro-dólar en 1971, Richard Nixon hizo una "operación" que a la larga es más que eso, ya que hay elementos suficientes para establecer un significado: la moneda deja de ser una medida, a riesgo de que se "pierda la medida" de lo que la moneda misma representa, y, lo que es peor, de que se naturalice lo des-medido. Al mismo tiempo, la moneda deja de ser medida de valor en un momento en que la economía estadounidense comienza a perder competitividad. La dimensión de "reserva de valor" se extravía aún más en un país que no ahorra, "no atesora", como se dice en la expresión "atesorar", como "aquilatar" y, de paso, "valorar". Se busca beneficio sin aquilatar, sopesar, ponderar, atesorar ni valorar. Aunque vaya perdiendo capacidad productiva, la economía estadounidense se impone en las representaciones como "eterna potencia" por la masa, olvidándose cómo se genera y cuál es la parte ficticia. Nixon convirtió el problema del valor en tabú, y no pasará mucho tiempo antes de que el trabajo también sea desvalorizado y deslocalizado: el creador de riqueza "no vale lo que pesa en oro". La decisión de 1971 no terminó ahí, puesto que el dólar fue devaluado. El poder de la moneda sale de la fuerza (otra vez, potencia) y la masa, y lleva al frecuente olvido de que las bases son cada vez más ilusorias. Nixon devaluó el dólar: el "valor" es algo que, a falta de patrón de medida objetivo (que no es pura convención, puesto que la economía estadounidense era la más productiva al momento de los acuerdos de Bretton Woods), es decidido en un juego de poder donde, además, no se juega limpio, puesto que quien tiene el poder no paga sus deudas, o decide como "saldar cuentas" con su propia moneda, el dólar, "por cuenta propia”: Estados Unidos decide arbitrariamente cómo se saldan esas cuentas y se reserva el derecho al fraude que el número-potencia legitima. Antropológicamente, se está de vuelta a la figura primitiva del trickster, el embaucador. Herman Melville hizo notar en El timador que lo propio de éste es apersonarse a pedir confianza, la del otro e incluso la de todos. 
A medida que "el dinero" parece imponerse, sucede que incluso la ciencia económica cree estar exenta de ideología, aunque sea un mecanismo ideológico hacer pasar una forma de hacer ciencia por la forma de hacerla: en el mismo orden de cosas que en la generalización del dinero, que pretende homogeneizar mediante vínculos que Zelizer llama de "cálculos instrumentalizables" (Zelizer, 2011: 2), lo que no entra en el cálculo es relegado como "narrativa". Tiende así a ejercer la dominación la ciencia que muestra lo mismo que Arthur Nussbaum había descubierto en el estadounidense, la habilidad para la experimentación monetaria y cuantitativa (ibid: 206). Zelizer indica que el sentido de lo que se hace queda erradicado (stampedout) con la nueva lógica cuantitativa que pregunta tan solo "cuánto es" y no "qué" ni "cómo" es.

Orléan recuerda que "la moneda [...] transforma las estimaciones privadas en valor socialmente reconocido" (Orléan, 2011: 170). Entonces puede haber anomalía donde se confunde estimación privada (el dólar) y valor socialmente reconocido: el trickster sostiene que su negocio es por el bien del otro o por el de todos, como lo hacen por cierto algunos intereses particulares en la ciencia. En la vida en sociedad, lo observado denota que para un fin particular se puede utilizar lo "socialmente reconocido" incluso sin deuda de ningún tipo (se toma sin devolver e incluso se afirma este derecho como el de "adquirir y consumir"); no queda cómo valorar en común, ni circuito social, ni más relación que la instrumentalización del otro-objeto, según reporte o no beneficio.

\section{BIBLIOGRAFÍA}

Aglietta, Michel; André Orléan et al. (1998), La monnaiesouveraine, París, Odile Jacob, pp. 398.

Arrighi, Giovanni (2007), Adam Smith en Pekin. Origenes y fundamentos del siglo XXI, Madrid, Akal, pp. 431.

Barton Perry, Ralph (1939), General theory of value, Cambridge, Harvard University Press, pp. 702.

Canetti, Elías (1981), Masa y poder, Barcelona, Muchnik Editores, pp. 492.

Friedrich, Otto (1995), Before the deluge. A portrait of Berlin in the 1920s, Nueva York, Harper, pp. 418.

Canguilhem, Georges (2005), Lo normal y lo patológico, México, Siglo XxI Editores.

Kelsen, Hans (1982), ¿Qué es justicia?, Barcelona, Ariel, pp. 217.

Kotler, Philip, y Gary Armstrong (2001), Marketing, México, Pearson, pp. 688. 
Pérez Romero, Luis Alfonso (2004), Marketing social. Teoría y práctica, México, Pearson, pp. 546.

Orléan, André (2011), L'empire de la valeur, París, Seuil, pp. 343.

Robbins, Lionel (1951), Ensayo sobre la naturaleza y significación de la ciencia económica, México, Fondo de Cultura Económica, pp. 214.

Rueff, Jacques (1964), El orden social, Madrid, Aguilar, pp. 577.

(1971), Le péchémonétaire de l'Occident, París, Plon, pp. 238.

Schmitt, Bernard (1977), L'or, le dollar et la monnaiesupranationale, París, Calmann-Lévy, pp. 227.

Triffin, Robert (1962), El oro y las crisis del dólar. El futuro de la convertibilidad, México, Fondo de Cultura Económica, pp. 206.

(1968), El sistema monetario internacional, Buenos Aires, Amorrortu, pp. 220.

Zelizer, Viviana (2011), El significado social del dinero, México, Fondo de Cultura Económica, pp. 274. 